\title{
PERANCANGAN IKLAN LAYANAN MASYARAKAT TENTANG PERILAKU MENJIPLAK MENGGUNAKAN MEDIA ANIMASI 2 DIMENSI
}

\author{
Muhammad Sabri ${ }^{1}$, Fuzi indraswary ${ }^{2}$ \\ Prodi Desain Komunikasi Visual \\ Fakultas Seni dan Desain Universitas Potensi Utama \\ shabry92@gmail.com ${ }^{1}$, fuziieindraswary@gmail.com²
}

\begin{abstract}
ABSTRAK
Menjiplak merupakan perilaku mencontoh hasil kerjaan orang lain,kemudian ikut menirunya, menjiplak ini tidak hanya di bidang penulisan saja, dibidang karya seni, prosuk fashion, teknologi dan lain sebagainya juga banyak terjadi, Cara menjiplaknya pun semakin lama semakin beragam dan canggih. Perilaku ini tidak hanya dapat merugikan orang pertama yang membuat namun juga dapat merugikan diri sendiri. Maka dari itu pentingnya sosialisai tentang menjiplak ini dan dampak negatif yang ditimbulkan dari kebiasaan menjiplak tersebut. Sosialisasi tentang menjiplak ini dibuat dalam bentuk iklan layanan masyarakat dengan media animasi 2 dimensi. animasi tersebut berdurasi 2 menit dengan format video mp4 yang memiliki kapasitas ukuran sebesar 60 MB yang dibuat dengan menggunakan software Adobe After Effects CC 2017.
\end{abstract}

Kata Kunci : Iklan Layanan Masyarakat, Menjiplak, Animasi 2 dimensi

\begin{abstract}
Copying is an example of the behavior of other people's work, then copying it, copying is not only in the field of writing, in the field of art, fashion products, technology and so on, it also happens a lot, how to copy it becomes increasingly diverse and sophisticated. This behaviorcan not only be detrimental to the first person who made it but can also be self-defeating. Therefore the importance of socialization about plagiarism and the negative impact arising from the habit of plagiarism. The socialization about tracing was made in the form of public service advertisements aith 2 dimensional animation media. The animation is 2 minutes long with the MP\$ video format which has a capacity of $60 \mathrm{MB}$ size which was created using Adobe After Effects CC 2017
\end{abstract}

Keywords : Copying, Public Service Advertising, 2 Dimensional Animation

\section{PENDAHULUAN}

Perkembangan teknologi dalam penyampaian informasi berkembang dengan sangat pesat hingga saat ini. Faktanya membuktikan bahwa banyak sekali inovasi teknologi terkait penyajian informasi, salah satunya adalah animasi. animasi merupakan alternatif tayangan video yang kini marak digunakan diberbagai media, baik televisi, videotron dan internet. Penggunaan animasi sebagai sarana penyampaian informasi perusahaan atau lembaga dan 
iklan layanan masyarakat dapat dilihat pada beberapa videotron yang terpasang disepanjang jalan raya. Videotron bukan hanya untuk media promosi saja, namun juga dapat menayangkan iklan layanan masyarakat seperti tentang buang sampah, tata tertip lalu lintas, narkoba dan lain-lainnya.

Menjiplak sepertinya sudah menjadi kebiasaan sebagian masyarakat, mulai dari bidang penulisan, dibidang karya seni, prosuk fashion, teknologi dan lain sebagainya juga banyak terjadi, Cara menjiplaknya pun semakin lama semakin beragam dan canggih, bahkan sekarang cukup dengan browsing di internet semuanya bisa kita cari. Bukan hanya dalam mengerjakan soal ujian. Parahnya lagi ditingkat mahasiswa, skripsi yang dibuat pun hasil menjiplak.

Perkembangan teknologi yang sangat pesat, membuat kemudahan didalam jaringan internet, terutama pada alat pencarian informasi seperti google, offline dictionaries serta berbagai aplikasi pendukung buku elektronik membuat siapapun mampu untuk mengakses informasi tanpa batas dimanapun dan kapanpun. Terdapat inovasi yang sangat luar biasa didalam kita mendapatkan sebuah data, yang memudahkan kita didalam menganalisa serta didalam meningkatkan hasil riset. Pesatnya perkembangan teknologi juga merupakan salah satu faktor dari sekian banyak penyebab tingginya tingkat plagiat. (Park 2003; Jackson 2006; Roig 2012; Scanlon \& Neumann 2002).

Untuk mengatasi masalah ini, maka harus dibuat sebuah media komunikasi yang dapat mensosialisasikan tentang menjiplak dan dampak negatifnya jika hal tersebut terus dilakukan. Ada berbagai macam cara untuk membuat media komunikasi, salah satunya adalah poster. Namun, media komunikasi tersebut dianggap kurang efektif dan kurang menarik. Oleh karena itu dibutuhkan suatu media komunikasi lain yang lebih efektif dan lebih menarik untuk dilihat oleh para audient.

Untuk itulah media komunikasi dengan Aminasi 2 dimensi dipilih sebagai salah satu media komunikasi yang efektif dan menarik karena bukan hanya teks saja namun dapat memuat campuran gambar yang bergerak, warna bahkan suara. Berdasarkan uraian diatas, maka pengkarya membuat iklan layanan masyarakat tentang kebiasaan menjiplak dengan menggunakan media Aminasi 2 dimensi. Pengkarya berharap dengan adanya karya ini masyarakat dapat lebih peduli akan kebiasaan menjiplak ini yang akan menimbulkan dampak yang negatif jika hal tersebut dibiarkan terus menerus.

\section{STUDI LITERATUR}

Iklan senantiasa dibuat sedemikian rupa dengan maksud untuk mempengaruhi secara menguntungkan pikiran maupun perasaan publik bagi suatu usaha atau perusahaan.Adapun definisi iklan menurut Rachmadi "Iklan ialah suatu bentuk komunikasi yang dimaksudkan untuk menginterpretasikan kualitas produk jasa dan ide-ide berdasarkan kebutuhan dan keinginan konsumen" (Rachmadi, 1993 : 36). 
Ditinjau dari perspektif komunikasi, iklan dianggap sebagai teknik penyampaian pesan yang efektif .Iklan dapat meyampaikan informasi yang dibutuhkan oleh khalayak. Adapun pengertian periklanan menurut Palapah dan Syamsudin ialah sebagai berikut "Periklanan atau advertising adalah sebagai penyebaran informasi mengenai suatu ide, gagasan, pelayanan atau produk yang mengaharuskan seseorang berbuat sesuatu sesuai dengan yang dimaksud oleh advertiser atau pemasang iklan" (Palapah dan Syamsudin, 1983 :47).

Iklan Layanan Masyarakat (ILM) adalah jenis iklan ynag bersifat nonprofit, jadi iklan ini tidak mencari keuntungan akibat pemasangannya kepada khalayak. (Liliweri, 31 : 1992).

Iklan Layanan Masyarakat adalah suatu jenis iklan yang dibuat dengan biaya yang tidak besar dan tidak komersial yang bertujuan untuk mempromosikan program - program ; kegiatan - kegiatan yang diadakan oleh pemerintah atau digunakan oleh organisasi organisasi kemasyarakatan yang non profit dan sebagai iklan yang berfungsi untuk kepentingan masayarakat, tidak termasuk acara prakiraan cuaca dan iklan promosi produk. Kasali (1995 : 201).

Perilaku adalah reaksi manusia terhadap suatu rangsangan yang dipengaruhi emosi atau perasaan saat menerima rangsangan. Sebagai reaksi, perilaku selalu berhubungan dengan dua pilihan, yaitu senang atau tidak senang, menuruti dan melaksanakannya, atau menjauhi dan menghindarinya, serta peranan pendidikan dalam pembentukan perilaku pada anak-anak sangat penting karena mempengaruhi perkembangan jiwanya dan pembentukan perilaku anak. Ellis S Robert dalam bukunya Educational Psychology, A Problem Approach (2000: 288).

Perilaku dibentuk oleh behaviorisme, situasi, dan keadaan sosial masyarakat, faktor personal berupa instink (naluri) yang menentukan perilaku manusia, misalnya, mengapa manusia berperang karena ada instink melawan, merebut dan berkelahi mengapa manusia membangun peradaban karena memiliki instink membangun, ketika seseorang meminjam uang terlihat lemah, tidak berdaya, tetapi ketika ditagih hutangnya berubah menjadi garang atau menghindar. Jadi, situasi atau lingkunganlah yang menentukan perilaku manusia atau seseorang. Edward Ross dalam bukunya Social Psychology dan dikutip kembali oleh Jalaluddin Rahmat dalam buku Psikologi Komunikasi (2005: 33).

Menurut kamus besar bahasa Indonesia (KBBI) Menjiplak merupakan menggambar atau menulis garis-garis gambaran atau tulisan yang telah tersedia (dengan menempelkan kertas kosong pada gamar atau tulisan yang akan di tiru); mencontoh atau meniru (tulisan pekerjaan orang lain); mencuri karangan orang lain dan mengaku sebagai karangan sendiri sendiri; mengutip karangan orang lain tanpa seizin penulisnya

Meniru dan mencontoh adalah perilaku belajar seorang anak berbuat atau bertingkahlaku meniru dari orang-orang di lingkungannya yang menurut pendapatnya 
berhasil terlepas apakah hal yang ditirunya perbuatan yang baik atau buruk, kata $\mathrm{Ny}$. Y. Singgih D. Gunarsa dalam buku Psikologi untuk pembimbing (2002:132).

Eric M. Anderman dan Tamera B. Murdock menjelaskan bahwa yang dimaksud menyontek (cheating) adalah melakukan ketidak jujuran atau tidak fair dalam rangka memenangkan atau meraih keuntungan. Mendefinisikan menjadi tiga kategori, 1.memberikan, mengambil, atau menerima informasi, 2. Mengunakan materi yang dilarang atau membuat catatan, dan 3. memanfaatkan kelemahan seseorang, prosedur atau proses untuk mendapatkan keuntungan dalam tugas akademik (Dodi Hartanto, 2012:4).

Menurut Ibiz Fernandes pengertian Animasi dalam bukunya Macromedia Flash Animation \& Cartooning: A creative Guide, "Animation is the process of recording and playing back a sequence of stills to achieve the illusion of continues motion" yang artinya adalah "Animasi merupakan sebuah proses merekam serta memainkan kembali serangkaian gambar statis untuk mendapatkan sebuah ilusi pergerakan.” ( Ibiz Fernandez, 2002).

Animasi merupakan suatu proses didalam menciptakan sebuah efek gerakan atau perubahan pada jangka waktu yang telah dibuat, serta terdapat juga sebuah perubahan warna pada suatu objek didalam jangka waktu tertentu serta dapat juga dikatakan sebagai perubahan bentuk dari suatu objek ke objek lainnya dalam jangka waktu tertentu (Bustaman, 2001).

Animasi 2 dimensi memiliki ukuran panjang (X-azis) dan ( Y-axis). Realisasi yang nyata didalam perkembangan dua dimensi yang cukup revolusioner yakni film - film kartun. Dan animasi 2D merupakan animasi yang menggunakan sketsa gambar, lalu sketsa gambar ini digerakkan satu persatu, maka tidak akan terlihat seperti nyata. Disebut animasi 2 dimensi karena dibuat melalui sketsa yang yang digerakan satu persatu sehingga nampak seperti nyata dan bergerak. (Bustaman, 2001).

\section{PEMBAHASAN}

Perancangan iklan layanan masyarakat dalam bentuk animasi 2 dimensi di mulai dari beberapa tahap yaitu sebagai berikut

\section{Concept}

Pada tahap ini dirumuskan dasar dasar dari proyek yang akan dikerjakan. Kegiatan yang dilakukan, antara lain menganalisa siapa yang akan menjadi target audience, merumuskan tujuan utama pembuatan animasi 2 dimensi, menganalisa bagaimana kesan yang akan ditampilkan kepada audience dll. Selanjutnya dilakukan pembuatan brief dari hasil brainstorming. Brief tersebut yang kemudian dijadikan sebagai acuan pembuatan storyboard untuk animasi perilaku menjiplak yang akan dikerjakan. 


\section{Design}

Tahap desain dalam pembuatan animasi 2 dimensi ini dilakukan secara spesifik, storyline yang telah dibuat selanjutnya divisualisasikan dalam bentuk gambar, rancangan tersebut disebut storyboard. Storyboard akan menampilkan seluruh gambaran material dan menampilkan setiap scene dari animasi 2 dimensi untuk iklan layanan masyarakat tentang perilaku penyontek. Gambar 1 berikut ini merupakan storyboard dari pembuatan animasi 2 dimensi untuk iklan layanan masyarakat tentang perilaku penjiplak.

Tabel 1. Storyboard

Sumber : Muhammad Sabri

\begin{tabular}{|c|c|c|}
\hline No & Gambar & Deskripsi \\
\hline 1 & $\underline{\text { MENJIPLAK }}$ & $\begin{array}{l}\text { Scene 1: teks "MENJIPLAK" } \\
\text { Teknik yang digunakan: scale, opacity, bounce, } \\
\text { trim path, rotation, position. }\end{array}$ \\
\hline 2 & 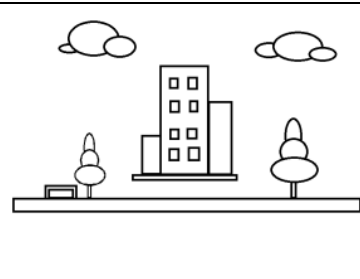 & $\begin{array}{l}\text { Scene } 2 \text { : menampilkan gedung sekolah atau } \\
\text { kampus, awan, kursi taman dan pohon. } \\
\text { Teknik yang digunakan: scale, opacity, bounce, } \\
\text { trim path, rotation, position. }\end{array}$ \\
\hline 3 & HARI INI KITA & $\begin{array}{l}\text { Scene } 3 \text { : menampilkan karakter guru atau } \\
\text { dosen, meja, papan tulis dan teks "hari ini kita } \\
\text { quiz ya" } \\
\text { Teknik yang digunakan: scale, opacity, bounce, } \\
\text { trim path, rotation, position. }\end{array}$ \\
\hline 4 & & $\begin{array}{l}\text { Scene } 4 \text { : menampilkan } 3 \text { karakter pelajar yang } \\
\text { sedang berfikir } \\
\text { Teknik yang digunakan: scale, opacity, bounce, } \\
\text { trim path, rotation, position. }\end{array}$ \\
\hline 5 & SANTAI TAPI PASTI & $\begin{array}{l}\text { Scene } 5 \text { : menampilkan karakter si Dudu dengan } \\
\text { teks "santai tapi pasti" } \\
\text { Teknik yang digunakan: scale, opacity, bounce, } \\
\text { trim path, rotation, position. }\end{array}$ \\
\hline
\end{tabular}




\begin{tabular}{|c|c|c|}
\hline 6 & & $\begin{array}{l}\text { Scene } 6 \text { : menampilkan tangan karakter pelajar } \\
\text { yang sedang browsing di aplikasi Chrome" } \\
\text { Teknik yang digunakan: scale, opacity, bounce, } \\
\text { trim path, rotation, position. }\end{array}$ \\
\hline 7 & UJIAN SELESAI & $\begin{array}{l}\text { Scene } 7 \text { : menampilkan karakter si Dudu dengan } \\
\text { teks "UJIAN SELESAI" } \\
\text { Teknik yang digunakan: scale, opacity, bounce, } \\
\text { trim path, rotation, position. }\end{array}$ \\
\hline 8 & 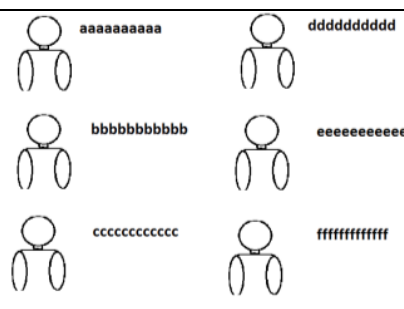 & $\begin{array}{l}\text { Scene } 8 \text { : menampilkan dampak-dampaknya } \\
\text { dalam bentuk teks dan gambar. } \\
\text { Teknik yang digunakan: scale, opacity, bounce, } \\
\text { trim path, rotation, position. }\end{array}$ \\
\hline 9 & $\begin{array}{l}\text { AKANKAH } \\
\text { INI } \\
\text { AKAN } \\
\text { TERUS } \\
\text { MEMBUDAYA }\end{array}$ & $\begin{array}{l}\text { Scene } 9 \text { : menampilkan teks "akankah ini akan } \\
\text { terus membudaya" } \\
\text { Teknik yang digunakan: scale, opacity, bounce, } \\
\text { trim path, rotation, position. }\end{array}$ \\
\hline 10 & back to your self & $\begin{array}{l}\text { Scene } 10 \text { : menampilkan teks "back to your self" } \\
\text { Teknik yang digunakan: scale, opacity, bounce, } \\
\text { trim path, rotation, position. }\end{array}$ \\
\hline
\end{tabular}

\section{Assembly}

Pada tahap ini, dilakukan proses pembuatan animasi 2 dimensi berdasarkan storyboard yang telah dibuat dan material yang telah dikumpulkan pada tahap sebelumnya. Pada proses pembuatan animasi ini, pembuatan dibagi menjadi 3 tahap, yaitu tahap designing, animating dan rendering.

\section{Designing}

Tahap designing merupakan proses pembuatan visual objek-objek yang menjadi material inti pembuatan animasi ini. Dilakukan proses pembuatan beberapa elemen yang dibutuhkan sesuai sketsa grafis yang telah tergambar pada storyboard yang telah dibuat sebelumnya. Berikut adalah beberapa objek gambar yang menjadi material pembuatan animasi ini 


\section{Gambar 1. Objek-objek material}

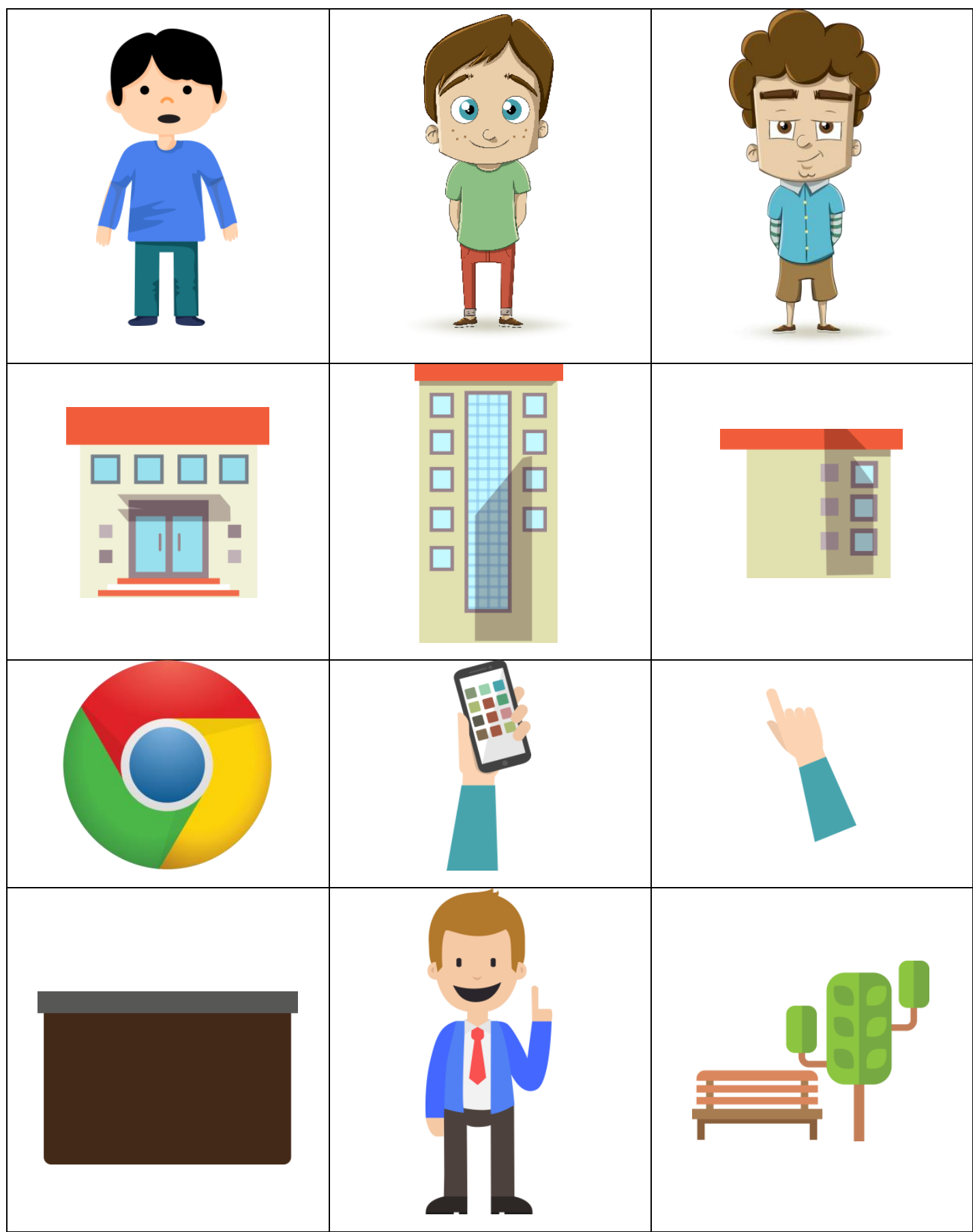

\section{Animating}

Animating merupakan proses menggerakan objek-objek still image agar terlihat seolah memiliki ilusi pergerakan. Proses animating untuk setiap scene memiliki teknik dasar yang relatif sama, yaitu menggunakan opacity, scale, position dan rotation. Penulis juga menggunakan beberapa effect dari Adobe After Effects CC 2017 pada beberapa scene, diantaranya $c c$ sphere, transition, masking, magnify, dll. Berikut adalah gambaran proses 
animating. Selanjutnya video setiap scene memasuki proses render animasi per scene. Gambar 2. menunjukan proses tahapan animasi.

\section{Gambar 2. proses tahapan animasi}
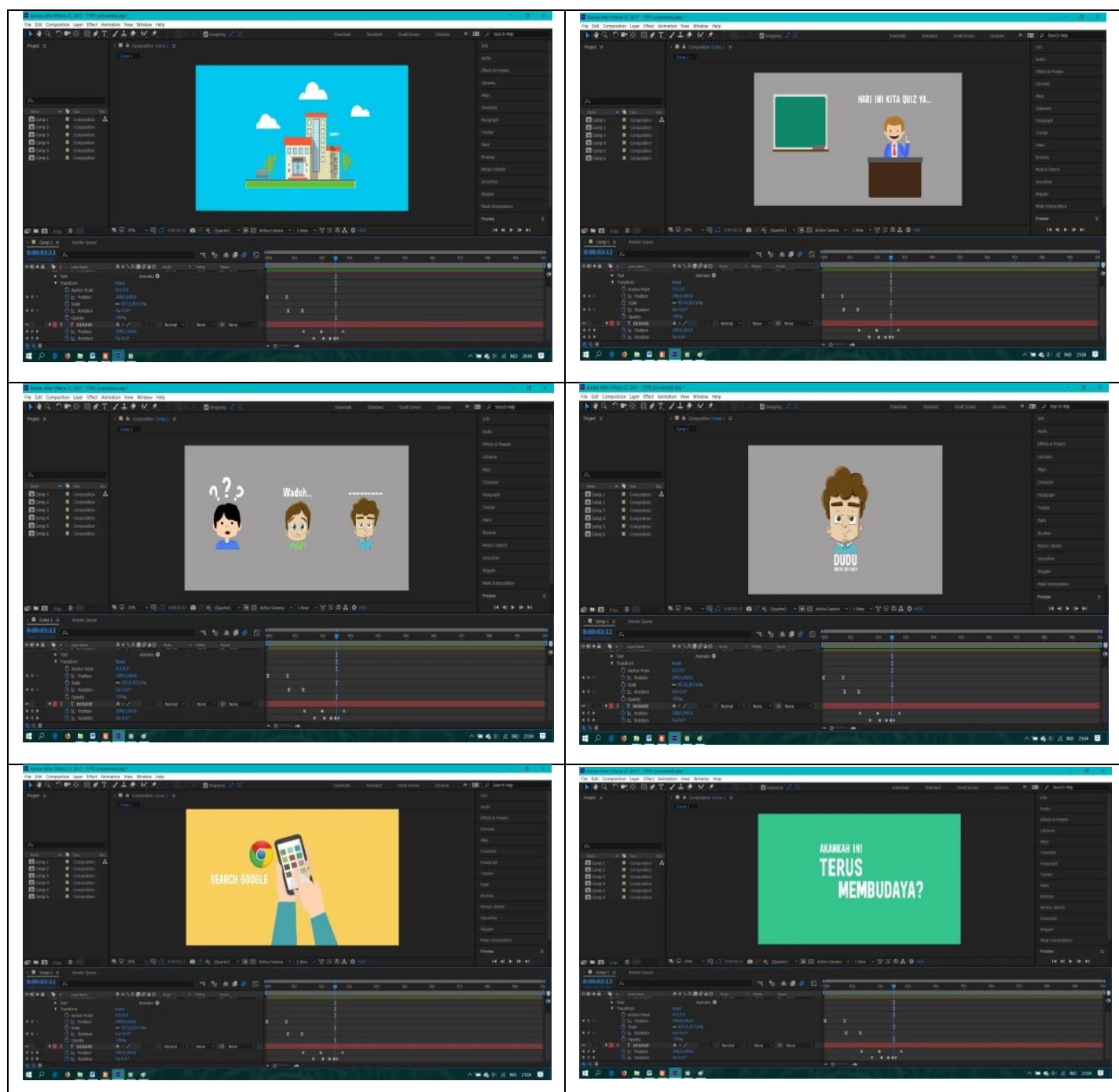

\section{Rendering}

Rendering pada Adobe After Effects CC 2017 merupakan proses terakhir yang dilakukan pengkarya untuk menghasilkan animasi 2 dimensi iklan layanan masyarakat tentang perilaku menjiplak. Rendering adalah proses export/ pengolahan akhir dari berbagai format file yang ada dalam composition Adobe After Effects menjadi format video.

\section{KESIMPULAN}

Menjiplak adalah perbuatan yang tidak jujur dan akan menjadi negatif jika hal tersebut terus menerus dilakukan. Maka dari itu dibutuhkan kepedulian dari semua orang, bukan 
hanya pelajar tersebut saja namun orang tua, guru dan dosen pun harus tegas dengan masalah jiplak menjiplak ini , agar masyarakat kita tidak menjadi orang yang pemalas, sehingga tidak menjadi kebiasaan bahkan menjadi budaya di negeri kita ini, dengan dibuatnya iklan layanan masyarakat ini semoga bisa mengurangi kebiasaan buruk tersebut.

\section{DAFTAR PUSTAKA}

[1] Bustaman. (2001). Web Design dengan Macromedia Flash Mx 2004. Yogyakarta: Andi Offset.

[2] Gunarsa, Singgih D, (2003). Psikologi Untuk Membimbing. Jakarta: BPK Gunung Mulia.

[3] Ibiz Fernandez, (2002). Macromedia Flash Animastion \& Cartooning: A Creative Guide. Hill/Osborn. California.

[4] Kamus Besar Bahasa Indonesia

[5] Kasali, Rhenald. (1995). Manajemen Periklanan-Konsep dan Aplikasinya di Indonesia, Jakarta : Pustaka Utama Grafiti.

[6] Liliweri. (1992). Dasar Dasar Komunikasi Periklanan. Bandung : Penerbit PT Citra Aditya Bakti.

[7] Palapah, M.O. dan Atang Syamsudin. 1983. Studi Ilmu Komunikasi, UNPAD

[8] Park, C. (2003). In other (people's) words: Plagiarism by university students - literature and lessons. Assessment and Evaluation in Higher Education, 28(5), 471-488.

[9] Rachmadi. (1993). Public Relation dalam Teori dan Praktek. Jakarta: Gramedia.

[10] Robert, Ellis.S, (2000). Educational Psychologi A Problem Approach. Jakarta: Gramedia.

[11] Roig, M. (2012). Can undergraduate students determine whether text has been plagiarized. The Psychological Record, 47(1), 113-122. 